\title{
Deformation of the Self-consciousness of Adolescents as a Consequence of Psychological Addiction to Computer Games
}

\author{
Inna V. Petrova ${ }^{1}$, Galina I. Efremova ${ }^{1}$, Elena V. Belovol ${ }^{2}$ \& Angelina A. Shagurova ${ }^{1}$ \\ ${ }^{1}$ The North Caucasus Federal University, Russian Federation \\ ${ }^{2}$ Moscow State Pedagogical University, Russian Federation \\ Correspondence: Inna V. Petrova, The North Caucasus Federal University, Fundamental and Applied Research \\ Institute, 1, Pushkina str., Stavropol, 355029, Russian Federation. E-mail: innakolotilova@mail.ru
}

Received: December 30, 2014 Accepted: March 19, 2015 Online Published: May 16, 2015

doi:10.5539/ass.v11n13p240

URL: http://dx.doi.org/10.5539/ass.v11n13p240

\begin{abstract}
This paper is devoted to the problem of psychological addiction to video games. Features of influence of video games on the self-consciousness of adolescents are indicated. Distinctions between dependent behavior and a condition of preoccupation with video games are specified. Results of work which was carried out in Russia are designated. The purpose of the study was to investigate the influence of computer games on the "self-image" teenagers. 233 adolescents aged 13-15 years acted in quality of probationers. The author's modification of the semantic differential was used to test assumptions about the similarity of "self-ideal" image and the image of the computer hero in adolescents, overly fascinated by video games. Factor analysis and cluster analysis was used as methods of data processing. The analysis of the content of modern popular video games was carried out. Features of the preventive work with adolescents, who are prone to addiction to video games, are described.
\end{abstract}

Keywords: addictive behavior, self-consciousness, virtual technologies, empirical study

\section{Introduction}

The problem of pathological dependences is one of the most actual problems of the present. Particularly acute is the problem of computer addiction among teenagers. The term "computer addiction" appeared in the mid 90-ies (Vaganov, 2000; Voyskunsky, 1999). Computer dependences are characterized by an irresistible desire to use the Internet and video games with the aim of escaping from reality. The problem of addiction to video games is one of the socially acceptable and poorly understood modern problems. According to researchers, about $12-14 \%$ of adolescents suffer from this disease (Mendelevich, 2007).

Video games are a component of life of the modern individual. According to international consulting companies "Newzoo", "Mail.Ru Group" and the American Association of Software and Video Games "Entertainment Software Association" in 2012-2013, young people in age of 13-35 years were the main audience of computer players. $15 \%$ of the audience of computer players is teenagers and young adults in ages of 13-17 years. Wherein it is the age of 13-15 years that is considered critical for the formation of anti-social behavior and dependencies (Bratus, 1988; Mendelevich, 2007). This is due to the fact that the world picture of a teenager is unstable. He is relying on the authorities, still forms the point of view of what is happening, and assimilates social norms and requirements (Ananiev, 1980; Elkonin, 1978; Erickson, 2006; Feldstein, 1988; Kon, 1978; Maksimenko, 2011; Shilstein, 2000; Stolin, 1983).

Preoccupation with video games leads to deformation of self-consciousness of adolescents. In this case, adolescents perceive the surrounding world through the filter of virtual reality. Therefore, computer games with illegal oriented for teenagers who are prone to addiction, become the exercise machine of asocial behavior.

\section{Literature Review}

According to psychologists and psychiatrists, adolescence is a critical age for the formation of pathological dependency and antisocial behavior (Akopov, 2008; Bratus, 1986; Mendelevich, 2007; Stepanov, 2001). This is due to the fact that the teenager forms a picture of the world, his/her own viewpoint of moral standards and requirements, looking for his/her place in life. The results of life trials can be differ. Sometimes the usual hobbies turn into dependence. Dependence began to form at the age of 12-15 in more than 55\% of alcohol, smoking and drug addicts (Babayan \& Gonopolsky, 1990). 
Video games attract 13-15 years old teenagers. It happens because in game there is chance for adolescents to estimate their opportunities, without focusing attention on conditional rules. Games are a way to show their capabilities and skills and allow one to try on adult roles. In the game teenager builds his virtual universe, similar to the adult world (Burlakov, 2000; Kolotilova, 2009).

Possibility of satisfaction of significant needs in game activity and bright emotional reinforcement promote fixing of addiction to video games (Shapkin, 1999). In this regard, states of "preoccupation with video games" and "pathological addiction to video games" should be distinguished (Kolotilova, 2009).

Preoccupation with video games is a psychological condition involving the use of a game as a mean of avoiding real-life problems, characterized by the experience of intense emotions. Playing a game more than 5 hours a day is typical for this state. Preoccupation with video games has specific psychological and physiological manifestations. Psychological criteria include: emergence of the "effects of the game" outside the game activity; thinking through the strategy of the game character, simulation of game moves outside the game; emotional involvement: experiencing feelings for the hero, for the process and the outcome of the game, player's tracking of his successes and failures in the game; feeling of "merge" with character during the game; the desire to be like the hero of the game; transferring planned affairs to the time after playing the game; difficulties with switching, concentration on not game activity; violation of behavior self-control; wellness or euphoria during playtime and (or) during thoughts about game; euphoria, good mood just before game; violation of social adaptation. Physiological criteria include: carpal tunnel syndrome, dry eye syndrome, headaches, back pain, irregular meals, neglect of personal hygiene, sleep disorders. Difference of preoccupation with video games from pathological dependence is in intensity of experienced emotions, frequency of using video games, as well as in the fact that personality changes in adolescents are not of a total character and they can be adjusted as a result of working with a psychologist and psychotherapist (Kolotilova, 2009).

Video games are used by teenagers with different goals: to develop skills, for relaxation, entertainment, and gaining new experiences, simulation of life experience, etc. At the same time preoccupation with games leads to deformation of the personality and distortion of the system of social relationships (Shapkin, 1999; Shmelev, 1998; Vasiliev, 1998; Voyskunsky, 1999). Adolescent perceives the world around him not through the prism of system of relations and not by solving social problems, but through the filter of virtual reality. This filter has an impact on the world outlook and attitude. World picture, the attitude to what is happening around, moral consciousness is the results of the comparison of their actions with actions of adults. Comparison happens as with real-life people, and with heroes of movies, books, video games. In this regard, games with an illegal aggressive orientation can become a peculiar exercise machine of asocial behavior for "morally unstable" teenagers, prone to addiction.

The study of the influence of video games on the transformation of "self-image" is impossible without the analysis of its components. When comparing a traditional and a video game a main character (game unit), game task, game actions, rules, game functions can be determined as components. When designing a picture of the world teenagers are inclined to be guided by subjects, authoritative for them (people or characters of books, movies, heroes of video games and so forth) (Feldstein, 1988; Kon, 1978; Shilstein, 2000). Therefore when studying changes of "self-image" the presentation of a hero of a video game, which role is assumed by teenagers in the course of game activity, has a key value.

The self-consciousness and self-conception are intensively formed in adolescence. In the Russian psychology, Ananiev, Stolin, Kon, and others studied the problems of "self-conception", "self-image", and self-consciousness (Ananiev, 1980; Kon, 1978; Stolin, 1983). Stolin (1983) considers the "self-conception" basing on Leontiev's and Ananiev's views (Ananiev, 1980; Leontiev, 1975). He views "self-conception" as a part of self-consciousness. Self-consciousness has a tiered structure. The levels are distinguished in accordance with the levels of an individually meaningful activity: the biological individual level, the social identities level and the personality level. At each level, the "self-image" has its own specificity. In particular, at the biological individual level, the organism "self-image" is formed. At the level of social individual, the "self-image" features are determined by the need for belonging to a society. The "self-image" forms in the process of assimilating social norms, values, etc. As a result, the system of social self-identities (gender, age, social-roles etc.) is formed. At the personality level, the central place in the "self-image" is given to the differentiating "self-conception" component. Stolin also pointed out the conflict essence of "self", which reflects the confrontation of different life relationships, motives, values. The "self" development occurs during inner work on the awareness of actions.

Burns integrated the foreign psychologist's views on the formation of "self-conception" (Burns, 1986). He compared various views of the occurrence and the essence of the phenomenon, and provided a description of the 
"system of self". "Self-conception" has a hierarchical structure. Burns identified three components of "self-conception": cognitive, evaluative and behavioral. "Self-conception" functions include ensuring intrapersonal coherence, interpreting experience, and forecasting events. "Self-conception" is dynamic. It is influenced by significant people, ideals, life experiences and culture.

In the structure of "self-conseption" Berns distinguished "self-real" and "self-ideal". "Self-real" is a representation of you. "Self-ideal" is an ideal representation of the person. "Self-ideal" function is to ensure self-control and socially approved behavior. Teens with unformed "self-ideal" lag behind in development because they are unable to control their actions. Such problems of adolescence as low adaptability and mental disorders result from the large discrepancy between the "self-real" and "self-ideal". According to Burns, "the others" images influence is important for adolescents "self-conception" formation (Burns, 1986).

Burns believed that the individual's activity direction is determined by the "self-conception" (Burns, 1986). However, he did not consider the factors that motivate a person to action and guide it. In this regard, we have studied Leontiev views on the self-consciousness formation (Leontiev, 1975). Leontiev considered that the activity is a source of personal development. For the self-consciousness development, the system of motives and system of personal meanings have special value. In the man's inner world, the formation of personal meanings occurs in the course of interaction. Thus, in the course of activity, all personality components, such as "self-conception", an image of the world and moral features are formed and developed.

In the study of "self-image" and presentation of a hero of a video game, we proceeded from the assumption that the process of the video game is an activity that is relevant to adolescents. In accordance with the view of Russian scientists, formation of implicit picture of the world and the development of human consciousness happens in course of activity (Aysina, 2011, Vygotsky, 1984; Leontiev, 1975; Petrenko, 1988, Rubinstein, 1999). Since a hero of a video game is a key figure involved in the process of the game, his image is a mental image that gets its content by refracting through the values system, worldview of adolescents gets a personal meaning for the teenager. As a result, image of a hero is an idealized representation of a teenager himself.

\section{Research Objectives}

To study the peculiarities of transformation of "self-image" in adolescents with varying degrees of preoccupation with video games.

\subsection{Hypothesis}

Preoccupation with video games leads to transformation of "self-image" at teenagers.

\section{Methodology}

Study of features of consciousness of teenagers was conducted in two stages. At the first stage, the author's version of technique of the semantic differential was designed. In the second stage features of pictures of themselves and of a hero of a video game among the adolescents with varying degrees of preoccupation with video games have been researched.

\subsection{Population and Sample}

To construct scales of semantic differential, 124 probationers in age of 13-15 years took part in the survey (31 girls and 93 boys). Research was conducted in Russia at comprehensive schools of Magadan, Moscow, the Moscow region, Perm. Internet users also took part.

Teenagers from the Moscow region, Magadan, Perm were interviewed for the purpose of studying the picture of themselves and of the hero of a video game. 109 13-15 years old probationers (48 girls and 61 boys) were participating.

\subsection{Instrument}

To test the hypothesis about the similarity of "self-ideal" image and the image of the video game hero in adolescents, preoccupied with video games, modification of scales of semantic differential was created (Kolotilova, 2009).

Source materials for the preparation of personal semantic differential were obtained from the analysis of the responses of adolescents to the question: "What qualities of heroes of role-playing games do you like? List at least three qualities". The study focused on role-playing video games. The player tries on the role of the virtual hero particularly in these games.

As a result of researching the answers, personal characteristics of heroes of video games that impose users were defined. The number of repetitions of each characteristic was counted at data processing. Microsoft Office Excel 
(2007) program was used to complete the task. 29 qualities with a frequency of repetitions from 5.65\% to $71.77 \%$ were called in total. Qualities with a frequency of repetitions from $5.65 \%$ to $14.51 \%$ were excluded from further consideration. Thus 20 characteristics which are designated in Figure 1 were selected for a basis of semantic differential.

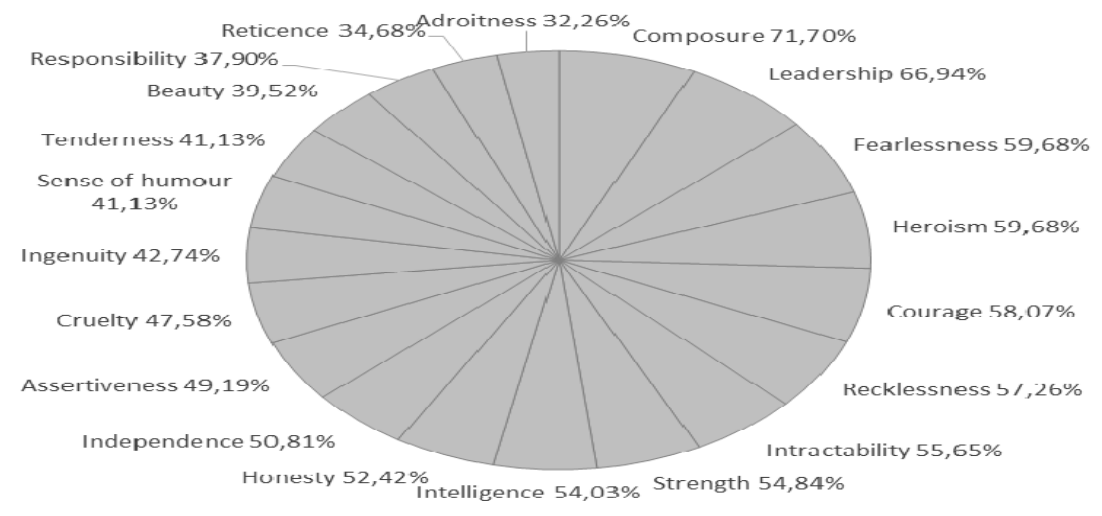

Figure 1. Characteristics of heroes of computer games

Figure 1 shows the number of repetitions of personal qualities as a percentage of the frequency of recurrence in respondents' questionnaire. Antonyms for 20 selected personal qualities were selected using dictionaries (Dal, 1998; Lvov, 1998; Volin \& Ushakov, 1935). Thus, 20 bipolar scales were formed by personal characteristics: with sense of humor-without sense of humor, heroic-cowardly, not indifferent-cool-headed, responsible-irresponsible, strong-weak, compliant-difficile, confident-non-confident, dexterous-clumsy, fearless-timid, courageous-shy, honest-criminal, humane-cruel, intelligent-inscrutable, beautiful-ugly, independent-dependent, sympathetic-indifferent, clever-silly, judicious-reckless, leading-lagging behind, talkative-silent.

These scales became a basis of semantic differential. With their help, we estimated "self-image" and presentation of a computer hero among teenagers.

For the purpose of studying the picture of themselves and of the hero of a video game teenagers should have estimated a picture of themselves at the moment ("self-real"), of what they would like to be ("self-ideal") and an image of the pleasant computer hero, on a gradually seven-point scale (3-2-1-0-1-2-3).

Before starting the estimation, probationers were divided into 2 groups. The amount of time allocated for a video game and systematic of game sessions formed the basis for allocation of groups. Teens that played the game no more than 0.5 hours per session were assigned to the first group-a group of teens who "are interested in video games". Psychological characteristics of teens of this group do not differ from the characteristics of adolescents who do not play video games. Teens that play regularly, more than 5 hours per day were assigned to the second group. For teenagers, "preoccupied with video games", a game becomes the "center" of their life, the most important side of existence. Study, communication with friends, relationship with parents fades into the background. Teens rarely communicate and mainly with those who is also fond of video games. Thus communication happens only to exchange computer disks or to learn information on games walkthrough, etc. This situation leads to formation of such personal and behavioral features, as: low self-control, explosiveness, instability of mood, sensitivity, difficulties with switching of attention and concentration on non-game activity, desire to resemble the hero of a video game, feeling of merge with the hero of game, experiencing emotional feelings for the hero, for his results in game, continuous thoughts on strategy of behavior of the game character outside the game, spontaneous and unconscious emergence of pictures from the game before eyes, music from the game, drawing a parallel between the events in the game and outside the game, good mood before playing the game, violation of social adaptation, hand pains, eyes dryness, headaches, back pains, irregular meals or the admission of meals, neglect of personal hygiene, sleep disorders and changes in sleep regime. Thus, life of the adolescents, preoccupied with video games, obeys the "rules" which the video game dictates.

\section{Results}

As a result of research of "self-image" and presentations of a computer hero among teenagers 6 mental images were received which were subjected to qualitative, factorial and cluster analyses for creation of semantic spaces 
and comparison of images of two groups of probationers.

We used the computer program SPSS (version 14.0 for Windows) for data processing.

The factorial analysis was carried out to define specifics of semantic space of "self-image" ("self-real" and "self-ideal") and an image of a hero of a role-playing video game among teenagers. The matrix of data fixing a current self-image, an ideal self-image and image of the hero of a video game among two groups of probationers was created. Factorization of the matrix was carried out by a method of main components with the subsequent rotation by Varimax method. Kayser's criterion was used at selection of significant factors, and also the non-randomness of valence for probationers was considered (excess of a 5\% contribution to the general dispersion of values). When determining the content of factors variables with value more than 0.50 were considered.

The comparative analysis of semantic spaces of current self-images ("self-real") among teenagers is reflected in Table 1.

Table 1. The comparative analysis of semantic spaces "self-real" at teenagers

\begin{tabular}{|c|c|}
\hline $\begin{array}{l}\text { Group } 1 \text { (teenagers who are interested in } \\
\text { computer games) }\end{array}$ & $\begin{array}{l}\text { Group } 2 \text { (teenagers who are preoccupied with } \\
\text { computer games) }\end{array}$ \\
\hline Factors, the weight of factors (\%) & Factors, the weight of factors (\%) \\
\hline 1. Empathy $(33,79)$ & 1. Fearlessness $(25,78)$ \\
\hline 2. Masculinity $(12,11)$ & 2. Pliancy of mind $(17,01)$ \\
\hline 3. Purposefulness $(10,57)$ & 3. Mutual understanding $(15,62)$ \\
\hline 4. Independence $(7,08)$ & 4. Inner-directedness $(10,12)$ \\
\hline
\end{tabular}

The analysis of semantic spaces of "self-real" among teenagers allowed to allocate four unipolar factors for each group. So, four factors which explained $63.55 \%$ of dispersion were allocated for the first group. Thus the semantic space of "self-real" of teenagers who are "interested" in video games is presented by factors which reflect aspiration to independence and orientation to society.

"Self-real" image among the adolescents who are preoccupied with video games is also presented by four factors with total dispersion of $68.53 \%$. The combination of satisfaction of ambitions and orientation to society is reflected in an inner world of teenagers.

Next, we will denote the semantic space of representations about "self-ideal" among teenagers in Table 2.

Table 2. The comparative analysis of semantic spaces "self-ideal" at teenagers

\begin{tabular}{ll}
\hline $\begin{array}{l}\text { Group } 1 \text { (teenagers who are interested in computer } \\
\text { games) }\end{array}$ & $\begin{array}{l}\text { Group } 2 \text { (teenagers who are preoccupied with } \\
\text { computer games) }\end{array}$ \\
\hline Factors, the weight of factors $(\%)$ & Factors, the weight of factors $(\%)$ \\
1. Trustworthiness $(50,04)$ & 1. Militancy $(44,35)$ \\
2. Pliancy of mind $(9,01)$ & 2. Superficiality in communication $(16,07)$ \\
3. Communicativeness $(7,59)$ & 3. Absorption into the inner world $(11,27)$ \\
4. Compliance $(5,89)$ & 4. Talkativeness $(10,63)$ \\
\hline
\end{tabular}

Table 3. Comparative analysis of the semantic space of the image of the hero in adolescents

\begin{tabular}{ll}
\hline $\begin{array}{l}\text { Group 1 (teenagers who are interested in } \\
\text { computer games) }\end{array}$ & $\begin{array}{l}\text { Group } 2 \text { (teenagers who are preoccupied with } \\
\text { computer games) }\end{array}$ \\
\hline Factors, the weight of factors (\%) & Factors, the weight of factors (\%) \\
1. Superficiality $(26,66)$ & 1. Charisma $(30,96)$ \\
2. Militancy $(17,16)$ & 2. Unemotionality $(26,59)$ \\
3. Domination $(15,26)$ & 3. Pliancy of mind $(12,40)$ \\
4. Contemplation $(11,00)$ & 4. Love of freedom $(10,78)$ \\
\hline
\end{tabular}


Four factors with general total dispersion of $72.53 \%$ are allocated in semantic space of "self-ideal" among teenagers from the first group. The presented factors indicate aspiration to interaction in society.

Let us consider "self-ideal" image among teenagers of the second group. Four components were allocated as a result of the factorial analysis. The total variance accounted for $82.32 \%$. Results can speak about orientation to outer side of communication which is combined with absorption in teenagers own experiences.

Results of the analysis of semantic space of representation of teenagers of an image of the hero of a video game are reflected in Table 3.

Four factors for each group of probationers were received as a result of the factorial analysis. We should say that negative characteristics were noted (taciturn, slow-witted, intractable, without sense of humor) in the description of the image of the hero of the game.

In the description of the image of a video game hero typical for adolescents from a group interested in video games, the total accumulated dispersion factors was $72.53 \%$. Representation of the hero includes such properties as militancy, domination, superficiality and contemplation. The self-preoccupation, focus on their understanding of what is happening is the central feature in this complex.

In the description of the image of a video game hero among teenagers who are preoccupied with video games, the share of the general dispersion of factors was $80.73 \%$. The image of the hero of a video game is presented by characteristics of "aggressive loner hero" which meaning of life is in battles, in overcoming obstacles, aspiration to freedom.

Procedure of the cluster analysis was carried out to define similarity degree between "self-real" image, "self-ideal" image and the image of a hero of a video game in the field of consciousness of teenagers of two experimental groups. We chose Euclid's square of distance as a way of measurement of distance between objects. Formation of clusters was carried out by a merge method. As a result we received two dendrogramma.

Results of the hierarchical cluster analysis of semantic fields of "self-real" image, "self-ideal" image and an image of a video game hero of a group of teenagers who are interested in video games are designated in Figure 2. Distance between objects and name of objects, which participated in a clustering, are designated on a clustering tree.

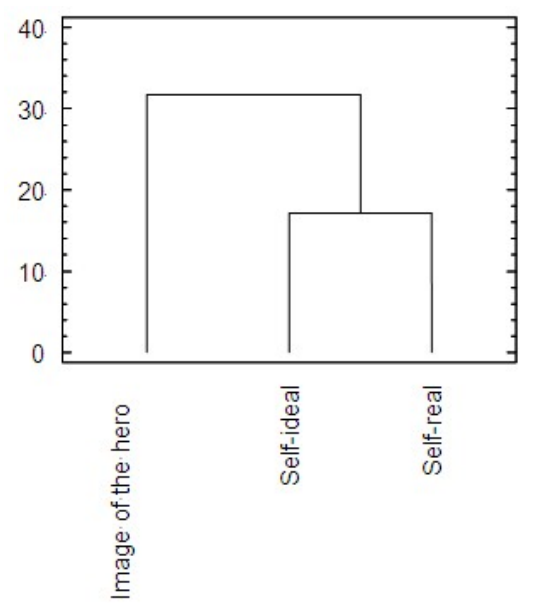

Figure 2. Results of the cluster analysis for group of the teenagers who are interested in computer games

In Figure 2, it is visible that objects were grouped in two clusters as a result of clustering. Thus, "self-real" image and "self-ideal" image are united in one cluster, and the image of a hero of a video game is in the second cluster.

Components of "self-image" ("self-real", "self-ideal") and "an image of the hero" of a video game among the teenagers who are preoccupied with video games also underwent the cluster analysis. Received data is presented in the clustering tree form in Figure 3. Names of objects and distance between them in a semantic field of consciousness of teenagers are marked on a dendrogramma. 


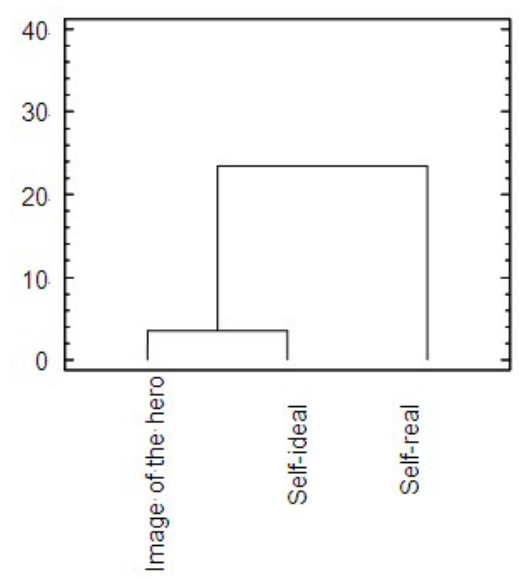

Figure 3. Results of the cluster analysis for group of the adolescents who are preoccupied with computer games

From the indicators reflected in Figure 3 it is visible that two clusters were allocated. First cluster represents "self-ideal" image and an image of a hero of a video game. The "self-real" image is in the second cluster.

\section{Discussion}

The content of semantic spaces of "self-real" image among teenagers is shown in Table 1.

For teenagers from the group "interested in video games" the content of factors is presented by characteristics which reflect an orientation of the personality on assistance and support for people around, compliance with the principles of morals, commitment and independence in behavior. The aspiration to understand others, peculiar to teenagers of this group, confirms the thought that such important mechanism of consciousness as a personal reflection, is formed during the considered age period (Feldstein, 1988; Vygotsky, 1984).

The combination of satisfaction of internal ambitions and orientation to society is reflected in an inner world of the teenagers preoccupied with video games. The small differentiation of factorial structure of "self-real" image can be caused by preoccupation with the virtual environment which, despite the game developer's attempts is rather monotonous.

We note the general tendencies that are common to both groups of probationers.

1) Groups of probationers include both boys and girls. However masculine lines of the personality are mainly reflected in the content of scales. This indicates a leveling of significance of feminine traits and a dominance of masculinity in contemporary society. We can assume that this fact indicates possibility of change of sex-role behavior among girls.

2) The overall positive background of self-images is inherent in both groups of probationers. Filling of factors speaks about an absence of dissatisfaction with themselves among teenagers, which may be a result of insufficient criticality of teens.

Semantic spaces of "self-ideal" image among teenagers are designated in Table 2.

"Self-ideal" image among teenagers who are interested in video games is presented by the characteristics reflecting: responsibility for the acts, care of other person with accordance to the law, aim at overcoming the obstacles, judiciousness, communicative openness, following the requirements and rules of society.

"Self-ideal" image among the adolescents, preoccupied with video games is presented with qualities which indicate the domination of vigor, aspirations to be ahead, social dispassionateness, absorption in own experiences. Results of comparison of semantic spaces of "self-ideal" image indicate a considerable difference in the content of a vector of life orientation: teenagers who play games for 0.5 hours a day and who do not play systematically, are focused on interaction with people around. The teenagers who play games more than 5 hours a day, emphasize auto-communication.

Content of semantic spaces of an image of a video game hero is shown in Table 3.

The semantic space of presentation of a hero of a video game among teenagers who are interested in video games is presented by descriptors which indicate external appeal and insufficient flexibility of mind, fearlessness, riskiness, pursuit of personal goals at the expense of others, insufficient emotionality and self-absorption. 
At the same time, the adolescents, preoccupied with video games estimate the hero as the leader ready to lead an army or a group of people, who is emotionally reserved, with developed powers of thinking and who is independent in decision-making.

Thus, there are distinctions in the content of ideas about the hero of a video game among both groups of probationers. The teenagers who are interested in video games describe an image of the hero as an image of externally set object. The computer hero isn't personally significant as the idea about him differs from "self-real" and "self-ideal" images among teenagers. Adolescents are more objective in judgments about the character; they are not trying to exaggerate and to idealize it. At the same time, teenagers from the second group treat the hero as "other significant" as his image is similar to descriptions of "self-ideal" image. In this regard we can assume that divergences in images are a consequence of absorption of teenagers into the world of video games and therefore, the sphere of communication and purview is narrowed.

Besides lack of such scale as "honest-criminal" is characteristic for "self-real" image and "self-ideal" image among teenagers from the second group. At the same time, "honest" quality is present in "self-real" and "self-ideal" images among teenagers from the first group and it is presented in the first factor. This implies that this descriptor is displaced from the field of consciousness. It is not significant for the second group of adolescents. Such situation can be explained by the content of popular video games where the main character breaks the law and remains unpunished (Dead Space 3, Battlefield 4, Assassins Creed 4 Black Flag, Grand Theft Auto $\mathrm{V}$ etc.).

When determining the degree of similarity and distinction between "self-real" image, "self-ideal" image and image of a hero of a video game in the field of consciousness of teenagers of two experimental groups it is possible to specify the following.

It is visible in Figure 2 that "self-real" and "self-ideal" images are united in one cluster, and the image of a hero of a video game is in the second cluster among the teenagers who are interested in video games. It means that semantic spaces of self-images of teenagers are nearby at the moment and in the future and it means that these images are similar. At the same time, as we found out as a result of the factorial analysis, the image of a hero of a role-playing video game differs in content from "self-images" of groups of teenagers who are interested in video games.

Figure 3 indicates that "self-ideal" image and the image of a video game hero are combined into one cluster among adolescents, preoccupied with video games. At the same time, "self-real" image of teenagers is located in another cluster. This indicates that adolescents see their ideal in the same way they see a video game hero.

Thus, we can say that group of teenagers who are interested in video games don't perceive an image of a computer hero as significant image. The adolescents, preoccupied with video games, identify themselves with the hero of a role-playing game. It is comparable to results of researches in which probationers at the age of 5-6 and 15-19 years participated. For example, emotional component of adolescents attitude to video games was studied (Evstigneeva, 2003). One of conclusions of an experiment was in the following: in the course of game the compassion for the hero and fear for themselves arises among teenagers. This experience is the result of the identification of the player and the game role. Also, influence of a game experience on features of the identity of 17-19 years old users was studied (Burmistrov, Shmelev, \& Fomicheva, 1991). Conclusions of research specify that transformation of "self-image" occurs among the most skilled players. "Self-ideal" and "self-real" images merge and represent the phenomenon of "self in a video game" among experienced users. Thus, the video game allows the user to become a whole with the character of game. Wherein, identification is a condition of the formation of personal significance of the hero and, as a consequence, the basis of changes of "self-image" among teenagers.

Results of the comparative analysis of "self-image" and image of a hero of a video game among two groups of probationers allow to assume that teenagers from group of the interested in video games represent themselves as independent and focused on society. Ideally, they want to be successful in interacting with other people. Teenagers see a hero of a video game as aggressive, absorbed by himself, focused on his own ideas about what is happening.

Preoccupied with video games teens view themselves as ones seeking to satisfy their own ambitions and, at the same time, focused on interaction with others. Ideally, they want to be militant, focused on the outer side of communication and self-absorbed. Video game hero for them is the loner hero living in battles, overcoming the obstacles, striving for freedom, using all possible means.

As the descriptions of "self-ideal" image and image of a video game hero among the adolescents, who are 
preoccupied with video games, are similar, we can assume that there is an identification of teenagers with the hero of game. At the same time video game heroes with positive personal qualities are idealized by them.

In 2014, we carried out the analysis of the content of the most popular video games that were rated as such by readers of media magazines and the Internet sites "Igromania" GameGuru, MetaGames. The results show the following. Main character (characters) of the game are: a vampire ("Castlevania: Lords of Shadow 2"), a robber, an alcoholic robber and a young man from a dysfunctional family ("Grand Theft Auto 5"), a smuggler and a teenage girl ("The Last of Us "), the commander of a tank crew ("World of Tanks"), a character with given player characteristics ("World of Warcraft"). Genres and orientation of games differ, but the game tasks are similar. Players need to investigate the virtual world and destroy (or capture the base of) the opponent. Operational and technical side of the game actions is conserved, and each symbol in the game has a specific value. The game rules are conditional. Functions of the game are not clearly defined by developers. As a rule, players determine the appointment of game activity on their own: recreation, building skills, relationships simulation and so on.

Often, the behavior of characters of popular games is a negative example for others to follow. Characters use profanity in speech; sometimes they lead a criminal life. Undoubtedly, besides video games, other different factors affect the development of the personality of adolescents (family, peer groups, the media, etc.). However, the results of an experiment conducted in the 70s of the twentieth century say in favor of the idea that a change in "self-image" occurs as a consequence of preoccupying with video games. (Liebert \& Sprafkin, 1970). Liebert and Sprafkin studied the impact of television programs of the aggressive, neutral and pro-social contents on behavior of 3-5 year-old children. Researchers came to a conclusion that children learn to behavior showed by a model. Considering the fact that a video game is an activity during which transformation of mental features of the user happens, we can speak about those video games promotes changes of "self-image".

Thus the pole of moral values is changing in the self-consciousness of teenagers, who regularly play video games for more than 5 hours per day: behavior that is unacceptable in a society is close for teenagers, becomes kind of standard. As a result distortion of "self-image" happens. It can lead to even bigger isolation of teenagers in society and to formation of illegal behavior (Kolotilova, 2011).

\section{Conclusion}

Video games interest teenagers because of the following reasons: first, they give the chance to meet the needs, actual for this age: freedom of action, independence in decision-making, self-search through playing different social roles; second, they allow to compensate own dissatisfaction with real life by accommodation of "successful" life of a hero of a game; third, they possess realness, and it is an condition of immersion in virtuality.

These features of games are conditions which promote leaving from objective reality. They provoke teenagers to substitute, artificial meet of needs.

Deformation of "self-image" of teenagers is a consequence of preoccupation with video games.

The special attention for a solution of the problem of formation of socially acceptable dependences should be paid to prevention of computer addiction. Preventive work involves building models of complex psychological and pedagogical assistance. The target audience is teenagers who are prone to addiction. Prevention is carried out by joint efforts of psychologists, teachers and parents.

There are three components of the developing work with teenagers: educational, psychological and social. The purpose of an educational component is in formation of knowledge of specifics of computer addiction, its influence on development of the personality. The purpose of a psychological component is in correction of the psychological features of the personality, promoting emergence of addictive behavior (sense of guilt, fear of changes, self-uncertainty, irresponsibility, an inadequate self-assessment, inability to establish relations with people around, etc.). The purpose of a social component is to help teenagers with social adaptation of (to create the sphere of hobbies, to diversify leisure interests and to improve relations with family, close friends). The main objectives of prevention of computer addiction are: development of any regulation of behavior; formation of autonomy in decision-making and responsibility for their actions; mastering skills of reflection; formation of a positive attitude towards themselves; development of confident behavior; mastering the skills of effective interpersonal interaction; the formation of an adequate worldview.

Thus, prevention of computer addiction is in changing the attitude, world outlook of a teenager, correction of self-perception and perception of other people.

Teen age is important for the development of personal characteristics, assimilation of specificity of interpersonal interaction, comprehension of the laws of society. In turn, the immersion in the game is associated with social 
exclusion. Lack of social mediation in the game leads to the fact that user analyzes what is happening on his own, based on his own ideas about the moral and ethical values. In this case, the game helps to perpetuate the negative behavioral patterns and deformation of components of personality and world outlook. Preoccupation with video games can lead to the formation of pathological dependence. This, in turn, has a negative impact on the mental health of adolescents.

\section{Acknowledgements}

This article was prepared as part of the task $\# 25.1815 .2014 / \mathrm{K}$ of 11.07 .2014 , on performance of the research work within the project framework of the state assignment in the field of scientific activity.

\section{References}

Akopov, A. Yu. (2008). Freedom from addiction. St. Petersburg: Rech

Ananiev, B. G. (1980). Selected psychological works. Moscow: Pedagogica.

Aysina, R. M. (2011). The possibility of using the contextual approach in teaching students of psychology. Bulletin of the State University of Management, 10, 4-6.

Babayan, E. N., \& Gonopolsky, M. H. (1990). Narcology. Moscow: Medicine.

Bratus, B. S. (1988). Abnormalities of personality. Moscow: Mysl.

Burlakov, I. V. (2000). Homo Gamer: The Psychology of computer games. Moscow: Independent firm "Class".

Burmistrov, I. V., Shmelev, A. G., \& Fomicheva, Y. V. (1991). Psychological correlates of keenness on computer games. Vestnik $M U, 14(3), 27-39$.

Burns, R. (1986). The Development of self-concept and parenting. Moscow: Progress.

Dal, V. I. (1998). Explanatory dictionary of living great Russian language (Vol. 2). Moscow: Russian language.

Elkonin, D. B. (1978). Psychology of the game. Moscow: Pedagogica.

Erickson, E. (2006). Identity: youth and crisis. Moscow: Moscow Psychological and Social Institute.

Evstigneeva, Yu. M. (2003). Psychological features of the reference to computer games in adolescence. Unpublished PhD thesis. Moscow State Pedagogical University, Moscow, RF.

Feldstein, D. I. (1988). Psychological features of personality development in adolescence. Voprosy psychologii, 6, 31-41.

Kolotilova, I. V. (2009). Individual psychological characteristics of adolescents, overly fascinated by role-playing computer games. Unpublished $\mathrm{PhD}$ thesis. Russian state social University, Moscow, RF.

Kolotilova, I. V. (2011). Features of formation of dependent behavior at teenagers. Social Policy and Sociology, 7, 234-244.

Kon, I. S. (1978). Revelation "self". Moscow: Publishing House of Political Literature.

Leontiev, A. N. (1975). Activity. Consciousness. Personality. Moscow: Politizdat.

Liebert, R. (1970). Television and social learning: Some relationships between viewing violence and behaving aggressively (overview). In J. Y. Murray, \& E. Rubinstein (Eds.), Television and social behavior. Washington, D.C.: U.S. Government Printing Office.

Lvov, M. R. (1998). Dictionary of antonyms Russian language. Moscow: Prosveshcheniye.

Maksimenko, Zh. A. (2011). Diagnostics of social endowments through the self-concept of communicatively successful personality: look "from within". Scientific Notes of the Russian State Social University, 7, $112-118$.

Mendelevich, V. D. (2007). Guide addiktology. St. Petersburg: Rech.

Petrenko, V. F. (1988). Psychosemantics of consciousness. Moscow: Publishing house of MSU.

Rubinstein, S. L. (1999). Fundamentals of the general psychology. St. Petersburg: Piter.

Shapkin, S. A. (1999). Computer games: a new area of psychological research. Psychological Journal, 17(1), 86-102.

Shilstein, E. S. (2000). Features of presentation self at adolescence. Voprosy psychologii, 2, 69-78.

Stolin, V. V. (1983). Self-consciousness of the personality. Moscow: Publishing house of MSU. 
Vaganov, A. G. (2000). Total illusion of real space. Reflections on the topic: Computers and the Internet in modern and future life. Mir psychologii, 2, 90-102.

Vasiliev, B. M. (1998). Computer games. Training and psychological relief. Moscow: Knowledge.

Volin, B. V., \& Ushakov, D. N. (1935). Explanatory dictionary of Russian language (Vol. 1). Moscow: The Soviet encyclopedia.

Voyskunsky, A. E. (1999). Group game activity on the Internet. Psychological Journal, 17(1), 126-132.

Vygotsky, L. S. (1984). In D. B. Elkonin (Ed.), Issues of child (age) psychology (Vol. 4). Moscow: Pedagogica.

\section{Copyrights}

Copyright for this article is retained by the author(s), with first publication rights granted to the journal.

This is an open-access article distributed under the terms and conditions of the Creative Commons Attribution license (http://creativecommons.org/licenses/by/3.0/). 